\title{
Colon metal stents as a bridge to surgery had no significant effects on the perineural invasion: a retrospective study
}

Yinghao $\mathrm{Cao}^{1 \dagger}$, Ming Yang ${ }^{2+}$, Lizhao Yan ${ }^{1 \dagger}$, Shenghe Deng ${ }^{1}$, Junnan $\mathrm{Gu}^{1}$, Fuwei Mao ${ }^{1}$, Ke Wu${ }^{1}$, Li Liư ${ }^{3 *}$ and Kailin $\mathrm{Cai}^{1^{*}}$

\begin{abstract}
Purpose: The long-term oncological effects of self-expandable metallic stent (SEMS) as a "bridge to surgery" are contradictory, and perineural invasion was supposed to be enhanced by the stenting. In this retrospective study, we compared the perineural invasion and the oncological outcomes between the stent as a bridge to surgery (SBTS)- and emergency surgery (ES)-treated patients to evaluate the results of stenting on the perineural invasion.

Methods: The clinical data of patients with acute intestinal obstruction caused by colorectal cancer from January 2013 to January 2017 were retrospectively collected. Forty-three patients underwent semi-elective curative resection after endoscopic SEMS insertion, and sixty-three underwent ES. The adverse events and long-term follow-up outcomes were assessed. The clinicopathological characteristics, perineural invasion rates, and survival rates were compared between the two patient groups.

Results: Stent insertion resulted in significantly lower stoma rate (32.6\% vs $46 \% ; P=0.03$ ), post-operative overall complication rate $(11.6 \%$ vs $28.6 \%, P=0.038)$, and total hospital stay $(17.07 \pm 5.544$ days vs $20.48 \pm 7.372$ days, $P=$ 0.042). Compared with the ES group, there was no significant increase in the incidence of peripheral invasion in the SBTS group (39.5\% vs $47.6 \%, P=0.411$ ). No significant difference was noted in the survival rate and long-term prognosis between the SEMS and ES groups $(P=0.964)$. The technical success rate was $95.6 \%$, and the clinical success rate was $97.7 \%$.

Conclusions: Preoperative colon stenting was an effective transitional method for colorectal cancer patients with complete obstruction. Short-term stent implantation had no significant effect on perineural invasion in patients with CRC.
\end{abstract}

Keywords: Colorectal cancer, Complete intestinal obstruction, Self-expanding metal stent, Emergency surgery

\footnotetext{
* Correspondence: gracefulliuly@163.com; caikailin@hust.edu.cn

†Yinghao Cao, Ming Yang and Lizhao Yan contributed equally to this work. ${ }^{3}$ Department of Epidemiology and Biostatistics, The Ministry of Education Key Lab of Environment and Health, School of Public Health, Tongji Medical College, Huazhong University of Science and Technology, Wuhan 430022, Hubei, China

'Department of Gastrointestinal Surgery, Union Hospital, Tongji Medical College, Huazhong University of Science and Technology, Wuhan 430022, Hubei, China

Full list of author information is available at the end of the article
}

\section{Introduction}

Colorectal cancer (CRC) is one of the most common malignant diseases, with more than 1.8 million new cases and 881,000 deaths in 2018. It is responsible for about one in ten cancer deaths. CRC is the third most common cancer and the second leading cause of mortality worldwide [1]. Partial or complete intestinal obstruction occurs in $7 \%$ to $29 \%$ of all patients with CRC, particularly malignant obstruction caused by left colon

C C The Author(s). 2020 Open Access This article is licensed under a Creative Commons Attribution 4.0 International License, which permits use, sharing, adaptation, distribution and reproduction in any medium or format, as long as you give appropriate credit to the original author(s) and the source, provide a link to the Creative Commons licence, and indicate if changes were made. The images or other third party material in this article are included in the article's Creative Commons licence, unless indicated otherwise in a credit line to the material. If material is not included in the article's Creative Commons licence and your intended use is not permitted by statutory regulation or exceeds the permitted use, you will need to obtain permission directly from the copyright holder. To view a copy of this licence, visit http://creativecommons.org/licenses/by/4.0/. The Creative Commons Public Domain Dedication waiver (http://creativecommons.org/publicdomain/zero/1.0/) applies to the data made available in this article, unless otherwise stated in a credit line to the data. 
cancer [2, 3]. Obstruction caused by CRC is a clinical emergency that can rapidly lead to deterioration, and untimely relief of the obstruction can lead to 30\% mortality rate [4-6]. Self-expandable metallic stent (SEMS) can effectively relieve obstruction in case of acute obstruction, and it can reduce the incidence of fistula by changing emergency operation to limited operation [7, 8]. However, stent implantation is not completely safe. The common complications include perforation, stent displacement, and re-obstruction. The use of SEMS may adversely affect oncological results and even turn curable diseases into incurable ones [9]. The long-term oncological safety of SEMS in obstruction caused by CRC remains controversial. More consideration and research are needed on long-term oncological outcomes, such as survival after insertion of SEMS [10]. Therefore, in this study, we aimed to compare the perineural invasion and long-term oncological outcomes between SBTS- and EStreated patients.

\section{Methods}

\section{Selected patients and study design}

From January 2013 to January 2017, 169 patients (95 males and 74 females) with CRC patients complicated with complete intestinal obstruction visited at Wuhan Union Medical College Hospital. We retrospectively collected the demographic, clinicopathological, oncological, SEMS-related, and surgical and survival data of the patients. Patients with CRC complicated with complete intestinal obstruction were diagnosed using clinical and imaging examinations. Complete intestinal obstruction was defined as follows. First, colonoscopy showed that the intestinal cavity was completely blocked by tumours. Second, faeces and gases could not pass through. Third, physical examination showed evident abdominal swelling with pain and distension. Fourth, abdominal computed tomography $(\mathrm{CT})$ exhibited a narrow intestinal segment with evident dilation of the proximal intestinal cavity and collapse of the distal part. Moreover, abdominal orthostatic plain X-ray showed multiple air-fluid levels in the upper abdomen, massive gas shadow, and sign of intestinal obstruction. All included patients met three or four of these criteria.

Patients with the following conditions were excluded from the study: (1) colonic perforation, peritonitis, and septic shock; (2) multiple obstruction or small intestinal obstruction on abdominal CT; (3) coagulation dysfunction; and (4) those with severe cardiovascular and cerebrovascular diseases who could not tolerate endoscopic surgery and those who underwent stenting for anastomotic stenosis and anastomotic leakage after colon surgery were also excluded (Fig. 1). The study was

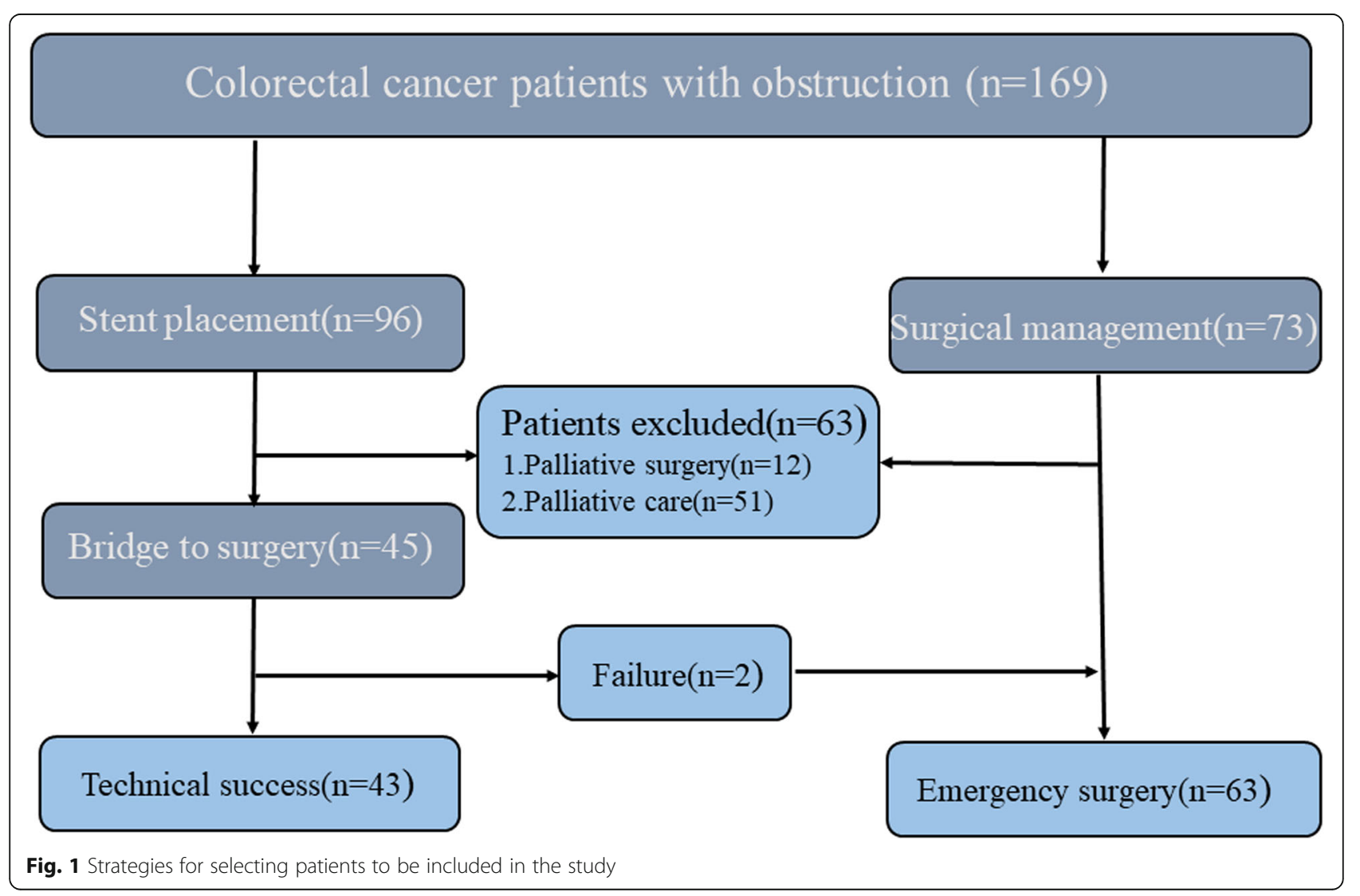


approved by the ethics committee of Wuhan Union Medical College Hospital (No. 2018-S377) and carried out in accordance with the Helsinki Declaration.

\section{Colonoscopic stenting procedure}

We used a one-person approach to colonoscopy in our centre. Stent placement was performed under both endoscopic and fluoroscopic guidance. Patients underwent cleansing enema for bowel preparation and received analgesia and sedation. We defined technical success as good placement and smooth expansion of stents under endoscopy and fluoroscopy. Clinical success was defined as intestinal decompression within $72 \mathrm{~h}$ after stent placement, with clinical and imaging evidence [11]. The main types of colon stents are Wilson Cook and Boston Scientific. The stent size and length were chosen according to the measured length of the obstruction, and uncovered SEMS was used as a bridge to surgery. The procedure was performed by endoscopists who had placed at least 25 colonic stents per year including palliative and bridge to surgery.

\section{Adverse events and management after stenting}

Patients with successful stent insertion without severe complications, such as bleeding and perforation, were administrated with liquid diet and other adequate nutrition support to optimize their nutritional status. Adverse events after stenting, such as intestinal perforation, stent displacement, re-obstruction, hematochezia, abdominal pain, and other complications, were defined as new symptoms after stent placement. ES should be immediately performed after confirmation of perforation. For patients with displacement and recurrence, we would initially observe their vital signs and performed stent implantation again if conditions permit. If the stent could not be placed, emergency operation or selective operation was performed according to the patients' conditions. Four patients with hematochezia and abdominal pain and fasting and rehydration methods were conducted, and the next treatment plan was determined according to their conditions.

\section{Emergency and elective surgery}

All patients who underwent ES received cleansing enema for bowel preparation. In patients undergoing surgery, including simultaneous metastasis resection (when metastasis was found before or during surgery), a detailed surgical plan was decided by the multidisciplinary team of our hospital after discussion. Patients with a stent as a bridge to surgery (SBTS) who had stable vital signs were discharged temporarily until the symptoms of obstruction were eliminated. Selective surgery could be performed within 1-4 weeks after a standard enema.

\section{PNI evaluation and oncology management}

Pathological staging was performed for all patients after surgery, and perineural invasion was analysed by specialist pathologists using 4-um-thick sections of tumour tissue fixed with $10 \%$ formalin and embedded in paraffin. PNI was defined the presence of viable tumour cells in the perineural space and the presence of perineural invasion with tumour cells invading into and/or with irregular destruction of the axon of the nerve bundles [12, 13]. Adjuvant chemotherapy was recommended for patients according to the guidelines of the Union for International Cancer Control. The detailed chemotherapy plan was designed by a professional oncology medical team in our hospital. Patients with local recurrence or distant metastasis of the tumours during 1-year followup after surgery were resected again.

\section{Follow-up and clinical results}

Follow-up data were obtained during clinical care for all patients, and it is conducted every 3 months. If the follow-up time was longer than 3 months, the data were updated by outpatient information or telephone interview. Patients who failed to attend the scheduled appointment within 1 year after the previous visit were considered lost to follow-up. The date of death and the cause of death were based on the patient's medical record or contact with their family members. Total survival rate (OS) was defined as the time interval from ES or SBTS to death or the last follow-up, whichever came first.

\section{Observation index}

The main indicators were perineural invasion rate and total survival rate of patients. The secondary observation indicators were as follows: technical success rate, clinical success rate, complications of stent placement after SEMS, total number of lymph nodes resected, number of positive lymph nodes, rate of adjuvant chemotherapy, operation time, amount of bleeding during the operation, post-operative hospital stay, and total hospital stay. The peritoneal infection rate, anastomotic leakage rate, mortality rate, temporary and permanent stoma rate (1 year after diagnosis), and primary anastomosis rate of all patients were analysed.

\section{Post-operative follow-up}

All patients enrolled in the study were followed up until they died or the last visit. Most patients were followed up in the clinic, using imaging, laboratory tests (magnetic resonance imaging, abdominal ultrasound, carcinoembryonic antigen, carbohydrate associated antigen 19-9, and positron emission tomography with CT), and digestive endoscopy. If the result was positive, a further 
endoscopic biopsy was performed to confirm the recurrence.

\section{Data analysis}

Continuous variables were presented as mean \pm standard deviation or median (interquartile range), and categorical variables were expressed as percentage. Students $t$-test was performed to compare the difference of continuous variables between the ES and SBTS groups. Chi-square test or Fisher exact test was used to compare categorical variables between the two groups. Univariate and multivariate logistic regression models were applied to assess the influence of operation methods on perineural invasion by calculating the odds ratios (ORs) and their corresponding 95\% confidence intervals (CIs). The cumulative survival probabilities of patients receiving ES or SBTS were estimated using the Kaplan-Meier method and compared with logarithmic rank test. Univariate and multivariate Cox proportional hazards regression models were used to evaluate the prognostic factors for overall survival by calculating hazard ratios and their 95\% CIs. All statistical analyses were performed using SPSS version 24 (Chicago, IL, USA) with two-sided $P<0.05$ as statistically significant.

\section{Results}

\section{Patient characteristics}

There were no differences in the demographic data between the two groups (Table 1). No significant differences were found in differentiation, $\mathrm{T}$ stage, $\mathrm{N}$ stage, tumour-node-metastasis (TNM) stage, total lymph node acquisition, number of positive lymph nodes, postoperative chemotherapy, and vascular invasion between the two groups. However, significant difference was observed in tumour locations. In the SEMS group, tumours were more common in the descending colon, sigmoid colon, and rectum, whereas in the ES group, tumours were more common in the caecum and ascending colon. Perineural invasion of the primary tumour was more frequent in the ES group (39.5\% vs $47.6 \%, P=0.411$ ) (Table 2 ). The metal stents were all uncovered with a length of $6-12 \mathrm{~cm}$, and the time from stent placement to elective surgery was 14.4 days (2-41 days). One patient underwent neoadjuvant chemotherapy before surgery, and radical surgery was performed 41 days after stent implantation (Table 3).

\section{SEMS-related adverse events}

Forty-three patients successfully underwent SBTS, and $42(97.7 \%)$ received clinical success. One patient developed an obstruction again after stent implantation, and stent re-insertion was performed. Complications occurred in 5 patients after implantation of SEMS, and stent perforation developed in 2 patients. These 2 patients suddenly developed abdominal pain and fever symptoms 1 week after surgery, and the abdominal Xray showed free air in the abdominal cavity.

Table 1 Demographic characteristics of the patients

\begin{tabular}{|c|c|c|c|c|}
\hline Characteristic & SBTS $(n=43), n(\%) /$ mean \pm sd & $\mathrm{ES}(n=63), n(\%) /$ mean $\pm \mathrm{sd}$ & Statistic & $P$ \\
\hline Age (years) & $62.19 \pm 12.72$ & $63.94 \pm 12.43$ & $-0.705^{a}$ & 0.668 \\
\hline Sex & & & $0.151^{b}$ & 0.697 \\
\hline Male & $25(58.1)$ & $39(61.9)$ & & \\
\hline Female & $18(41.9)$ & $24(38.1)$ & & \\
\hline $\mathrm{BMI}$ & $22.5 \pm 3.06$ & $22.5 \pm 2.77$ & $0.008^{a}$ & 0.194 \\
\hline ASA score & & & $0.172^{b}$ & 0.917 \\
\hline$\|$ & $30(69.8)$ & $46(73.0)$ & & \\
\hline 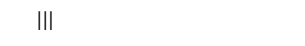 & $12(27.9)$ & $16(25.4)$ & & \\
\hline IV & $1(2.3)$ & $1(1.6)$ & & \\
\hline Comorbidity & 8 (18.6) & $13(20.6)$ & $0.066^{\mathrm{b}}$ & 0.797 \\
\hline Hypertension & $4(9.3)$ & $8(12.7)$ & & \\
\hline Diabetes & $2(4.7)$ & $2(3.2)$ & & \\
\hline Coronary heart disease & $2(4.6)$ & $4(6.3)$ & & \\
\hline Cerebral infarction & $0(0)$ & $1(1.6)$ & & \\
\hline Schistosomiasis & $0(0)$ & $2(3.2)$ & & \\
\hline Cirrhosis & $0(0)$ & $1(1.6)$ & & \\
\hline Hypoalbuminemia & $1(2.3)$ & $0(0)$ & & \\
\hline
\end{tabular}

ASA score American Society of Anesthesiologists score, sd standard deviation

${ }^{\mathrm{a}} t$-test

${ }^{\mathrm{b}}$ Chi-square test 
Table 2 Oncological outcomes of the patients

\begin{tabular}{|c|c|c|c|c|}
\hline Characteristic & SBTS $(n=43), n(\%) /$ mean \pm sd & $\mathrm{ES}(n=63), n(\%) /$ mean \pm sd & Statistic & $P$ \\
\hline Primary tumour site & & & $5.809^{b}$ & 0.055 \\
\hline Left colon & $25(58.1)$ & $31(49.2)$ & & \\
\hline Right colon & $7(16.3)$ & $23(36.5)$ & & \\
\hline Rectum & $11(25.6)$ & $9(14.3)$ & & \\
\hline Tumour differentiation & & & $0.203^{b}$ & 0.903 \\
\hline High & $5(11.6)$ & $7(11.1)$ & & \\
\hline Moderate & $30(69.8)$ & $42(66.7)$ & & \\
\hline Poor & $8(18.6)$ & $14(22.2)$ & & \\
\hline T stage & & & $0.256^{b}$ & 0.905 \\
\hline $\mathrm{T} 3$ & $17(39.5)$ & $23(36.5)$ & & \\
\hline T4a & $24(55.8)$ & $36(57.1)$ & & \\
\hline $\mathrm{T} 4 \mathrm{~b}$ & $2(4.7)$ & $4(6.3)$ & & \\
\hline$N$ stage & & & $0.987^{b}$ & 0.611 \\
\hline No & $16(37.2)$ & $23(36.5)$ & & \\
\hline N1 & $15(34.9)$ & $27(42.9)$ & & \\
\hline N2 & $12(27.9)$ & $13(20.6)$ & & \\
\hline TNM stage & & & $0.51^{\mathrm{b}}$ & 0.972 \\
\hline$\| \mathrm{A}$ & $8(18.6)$ & $10(15.9)$ & & \\
\hline$\| \mathrm{B}$ & $7(16.3)$ & $13(20.6)$ & & \\
\hline$\| \mathrm{II}$ & $18(41.9)$ & $25(39.7)$ & & \\
\hline 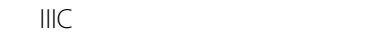 & $6(14.0)$ & $8(12.7)$ & & \\
\hline IV & $4(9.3)$ & $7(11.1)$ & & \\
\hline Total number of lymph nodes & $23.77 \pm 10.44$ & $20.00 \pm 8.489$ & $2.042^{\mathrm{a}}$ & 0.479 \\
\hline Number of positive lymph nodes & $3.12 \pm 4.537$ & $2.48 \pm 4.704$ & $0.698^{a}$ & 0.478 \\
\hline Adjuvant chemotherapy & & & $1.871^{\mathrm{a}}$ & 0.171 \\
\hline No & $23(53.5)$ & $42(66.7)$ & & \\
\hline Yes & $20(46.5)$ & $21(33.3)$ & & \\
\hline Perineural invasion & & & $12.915^{\mathrm{b}}$ & 0.411 \\
\hline No & $26(60.5)$ & $33(52.4)$ & & \\
\hline Yes & $17(39.5)$ & $30(47.6)$ & & \\
\hline Vascular invasion & & & $1.937^{b}$ & 0.164 \\
\hline No & $34(79.1)$ & $42(66.7)$ & & \\
\hline Yes & $9(20.9)$ & 21 (33.3) & & \\
\hline
\end{tabular}

${ }^{\mathrm{a}}$ t-test

${ }^{\mathrm{b}}$ Chi-square test

\section{Surgery}

In the SBTS group, $73 \%$ of the patients were discharged from the hospital within an average of 3 days (1-7 days) after endoscopic stent implantation, and $74.4 \%$ of the patients underwent laparoscopic resection of the tumour. Only $41.3 \%$ of the patients in the ES group underwent laparoscopic resection $(P=$ 0.03). Compared with the ES group, the temporary stoma rate and operation time in the SBTS group decreased significantly $(32.6 \%$ vs $46 \%, P=0.03$; $170.42 \pm 40.91$ vs $199.52 \pm 54.67, P=0.047)$. Post- operative hospital stay is defined as the length of hospital stay after surgery, and the median length of post-operative hospital stay was 12 days. Total hospital stay is defined as the total time of two or one hospitalization, and the median length of total hospital stay was 19 days. There was a significant difference between the two groups (12.65 \pm 5.28 vs 17.30 $\pm 6.30, P=0.030 ; 17.07 \pm 5.54$ vs $20.48 \pm 7.37, P=$ 0.042). The permanent stoma rates for the ES and SBTS groups were $2.3 \%$ and $6.3 \%$, respectively $(P=$ 0.337) (Table 3). 
Table 3 Clinical characteristic of the patients

\begin{tabular}{|c|c|c|c|c|}
\hline Characteristic & SBTS $(n=43), n(\%) /$ mean \pm sd & $\mathrm{ES}(n=63), n(\%) /$ mean $\pm \mathrm{sd}$ & Statistic & $P$ \\
\hline Operation time (minutes) & $170.42 \pm 40.91$ & $199.52 \pm 54.67$ & $-2.968^{\mathrm{a}}$ & 0.047 \\
\hline Volume of blood & $358.60 \pm 121.98$ & $375.10 \pm 114.33$ & $-0.710^{a}$ & 0.923 \\
\hline Abdominal access (\%) & & & $11.234^{\mathrm{b}}$ & 0.003 \\
\hline Laparoscopy & $32(74.4)$ & $26(41.3)$ & & \\
\hline Laparotomy & $10(25.6)$ & $32(58.7)$ & & \\
\hline Temporary stoma rate (\%) & & & $4.728^{\mathrm{a}}$ & 0.030 \\
\hline Yes & $14(32.6)$ & $29(46.0)$ & & \\
\hline No & $34(67.4)$ & $34(54.0)$ & & \\
\hline Permanent stoma rate (\%) & & & $0.921^{\mathrm{a}}$ & 0.337 \\
\hline Yes & $1(2.3)$ & $4(6.3)$ & & \\
\hline No & $42(97.7)$ & $59(92.7)$ & & \\
\hline Post-operative hospitalization (days) days & $12.65 \pm 5.29$ & $17.30 \pm 6.30$ & $-3.721 a$ & 0.030 \\
\hline Total hospitalization (days) & $17.07 \pm 5.54$ & $20.48 \pm 7.37$ & $-2.572 a$ & 0.042 \\
\hline Performed procedure & & & & \\
\hline Right hemicolectomy & $6(14.0 \%)$ & $28(44.4 \%)$ & & \\
\hline Transverse colectomy & $2(4.7 \%)$ & $3(4.8 \%)$ & & \\
\hline Left hemicolectomy & $13(30.2 \%)$ & $16(25.4 \%)$ & & \\
\hline Sigmoidectomy & $11(25.6 \%)$ & $10(15.9 \%)$ & & \\
\hline Radical resection of rectal cancer & $9(20.9 \%)$ & $4(6.3 \%)$ & & \\
\hline Hartman & $2(4.7 \%)$ & $2(3.2 \%)$ & & \\
\hline
\end{tabular}

${ }^{\mathrm{b}} \mathrm{Chi}$-square test

\section{Post-operative mortality and complications}

The 30-day mortality rates in the SBTS and ES groups were $0 \%$ and $1.6 \%$ ( 1 case), respectively. The incidence of post-operative complications in the two groups was $11.6 \%$ (5 cases) and $28.6 \%$ (18 cases). In the SBTS group, no patient mortality and no anastomotic leakage occurred after the operation. In the ES group, the postoperative overall mortality rate was $1.6 \%$ ( 1 of 63 patients), and the post-operative rate of anastomotic leakage was $4.8 \%$ (3 of 63 patients). Other early postoperative adverse events are listed in Table 4.

\section{Perineural invasion}

As previously mentioned, perineural invasion was more frequent in the ES group. Regardless of surgical methods, post-operative pathological results showed that 47 patients $(44.3 \%)$ had perineural invasion, and 59 patients $(55.7 \%)$ had no perineural invasion. No significant correlation was found between the occurrence of perineural invasion and age, gender, BMI, tumour size, tumour location, $\mathrm{T}$ stage, and total number of lymph nodes $(P>0.05)$ (Table 5). Patients with perineural invasion in $\mathrm{N}$ stage were more common in $\mathrm{N} 1$ and $\mathrm{N} 2$ (42.6\% and $36.1 \%$ vs $13.5 \%$ and $32.2 \%, P=0.003$ ).

Table 4 Post-operative mortality and complications of the patients

\begin{tabular}{|c|c|c|c|c|}
\hline Complications & SBTS $(n=43(\%))$ & $\mathrm{ES}(n=63(\%))$ & Statistics & $P$ \\
\hline Yes & $5(11.6)$ & $18(28.6)$ & 4.318 & 0.038 \\
\hline Wound dehiscence & $1(2.3)$ & $0(0)$ & & \\
\hline Wound infection & $1(2.3)$ & $5(79.4)$ & & \\
\hline Anastomotic leakage & $0(0)$ & $3(4.8)$ & & \\
\hline Pulmonary infection & $1(2.3)$ & $2(3.2)$ & & \\
\hline Thrombosis & $2(4.6)$ & $0(0)$ & & \\
\hline Hypoproteinemia & $2(4.6)$ & $12(19.1)$ & & \\
\hline Death & $0(0)$ & $1(1.6)$ & & \\
\hline No & $38(88.4)$ & $45(71.4)$ & & \\
\hline
\end{tabular}


Table 5 Clinicopathological features and tumour outcomes of patients with positive neurological invasion

\begin{tabular}{|c|c|c|c|}
\hline & $\mathrm{PNI}(+)(n=47)$ & $\mathrm{PNI}(-)(n=59)$ & $P$ \\
\hline$\overline{\text { Age }(\text { year })^{a}}$ & $61.98 \pm 10.898$ & $64.22 \pm 13.680$ & 0.219 \\
\hline $\mathrm{BMI}^{\mathrm{a}}$ & $22.57 \pm 2.465$ & $22.49 \pm 3.235$ & 0.173 \\
\hline $\operatorname{Sex}(\%)^{a}$ & & & 0.880 \\
\hline Male & $28(59.6)$ & $36(61.0)$ & \\
\hline Female & $19(40.4)$ & $23(39.0)$ & \\
\hline Tumour diameter $^{\mathrm{a}}(\mathrm{cm})$ & $4.45 \pm 1.364$ & $4.86 \pm 1.514$ & 0.572 \\
\hline T stage $(\%)^{b}$ & & & 0.466 \\
\hline T3 & $16(30.0)$ & $24(40.7)$ & \\
\hline T4a & $27(37.5)$ & $33(55.9)$ & \\
\hline T4b & $4(8.5)$ & $2(4.4)$ & \\
\hline$N$ stage $(\%)^{b}$ & & & 0.003 \\
\hline No & $10(21.3)$ & $29(49.2)$ & \\
\hline N1 & $20(42.6)$ & $22(32.3)$ & \\
\hline N2 & $17(36.1)$ & $8(13.5)$ & \\
\hline TNM stage $(\%)^{\mathrm{b}}$ & & & 0.012 \\
\hline$\| \mathrm{A}$ & $5(10.6)$ & $13(22.0)$ & \\
\hline$\| \mathrm{B}$ & $5(10.6)$ & $15(25.4)$ & \\
\hline$\| I B$ & $19(40.4)$ & $24(40.7)$ & \\
\hline$\| I I C$ & $10(21.3)$ & $4(6.8)$ & \\
\hline IV & $8(17.0)$ & $3(5.0)$ & \\
\hline Vascular invasion (\%) ${ }^{\mathrm{b}}$ & & & 0.000 \\
\hline No & $20(42.6)$ & $56(94.9)$ & \\
\hline Yes & $27(57.4)$ & $3(5.1)$ & \\
\hline Total number of lymph nodes ${ }^{a}$ & $20.87 \pm 11.301$ & $22.05 \pm 7.765$ & 0.211 \\
\hline Number of positive lymph nodes ${ }^{a}$ & $4.23 \pm 6.005$ & $1.54 \pm 2.028$ & 0.001 \\
\hline Primary tumour site & & & 0.728 \\
\hline Left colon & $23(48.9)$ & $33(55.9)$ & \\
\hline Right colon & $15(31.0)$ & $15(25.4)$ & \\
\hline Rectum & $9(19.1)$ & 11 (18.6) & \\
\hline
\end{tabular}

Table 6 Factors associated with PNI in colorectal cancer patients with complete intestinal obstruction

\begin{tabular}{|c|c|c|c|c|c|c|}
\hline & \multicolumn{3}{|c|}{ Univariate analysis } & \multicolumn{3}{|c|}{ Multivariate analysis } \\
\hline & $\overline{\mathrm{OR}}$ & $(95 \% \mathrm{Cl})$ & $P$ & $\overline{\mathrm{OR}}$ & $(95 \% \mathrm{Cl})$ & $P$ \\
\hline Stent $(\mathrm{Y} / \mathrm{N})$ & 1.39 & $0.63-3.05$ & 0.441 & 1.06 & $0.39-2.83$ & 0.906 \\
\hline Sex & 1.06 & $0.49-2.32$ & 0.880 & 1.17 & $0.44-3.11$ & 0.759 \\
\hline Age & 0.98 & $0.96-10.17$ & 0.256 & 0.97 & $0.93-1.01$ & 0.172 \\
\hline Lymph node metastasis & 3.58 & $1.51-8.50$ & 0.004 & 2.07 & $0.73-5.86$ & 0.168 \\
\hline Vascular invasion & 25.20 & 6.89-92.23 & 0.00 & 25.66 & $6.56-100.41$ & 0.000 \\
\hline
\end{tabular}


Patients with perineural invasion were more likely to be seen in stage IIIB patients and in patients with vascular invasion $(57.4 \%$ vs $5.1 \%, P=0.000)$. Meanwhile, the rate of perineural invasion was also higher in patients with more positive lymph nodes $(4.23 \pm 6.005$ vs $1.54 \pm$ 2.028, $P=0.001$ ) (Table 6).

\section{Long-term survival}

The permanent stoma rate was lower in the SBTS group than that in the ES group. Figure 2a depicts the KaplanMeier survival curve of the patients, and no difference was found in the Kaplan-Meier survival between the two groups $(P=0.964)$. The survival rate of patients without perineural invasion was higher than that of patients with perineural invasion and vascular invasion $(P$ $<0.001$, Fig. 2b). There were no significant between- group differences in the rates of overall survival $(P=$ 0.382 and $P=0.249$, Fig. $2 d, c)$.

\section{Prognostic factors}

Logistic regression analysis was used to analyse the factors affecting perineural invasion in patients with CRC. The results showed that the occurrence of perineural invasion was not related to whether the patient placed the stent, age, gender, or lymph node metastasis; and the incidence of perineural invasion was higher in patients with positive vascular invasion (OR 24.96, 95\% CI 6.43-98.47, $P<0.01$ ) (Table 6). Multivariate cox regression survival analysis showed that perineural invasion (HR 3.245, 95\% CI 1.46-7.20, $P=0.004$ ) was independent prognostic factors in patients with CRC (Table 7).
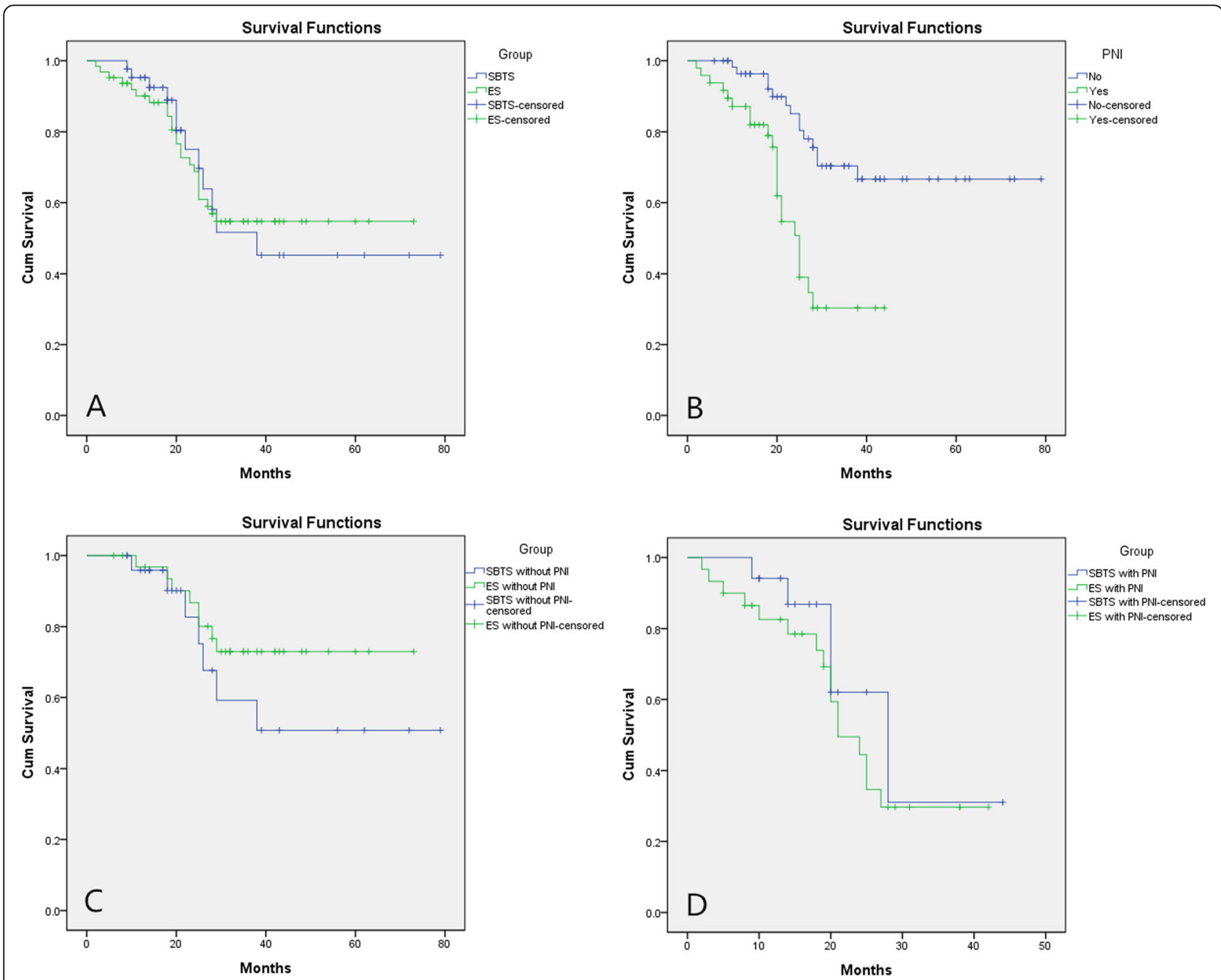

Fig. 2 Overall survival analysis. a Survival curve of patients with self-expandable metal stents as a "Bridge to Surgery" (SBTS group, $n=43$ ) and emergency surgery (ES group, $n=63, P=0.964)$. b Survival curve of positive and negative patients with perineural invasion $(P<0.01)$. c Overall survival for all patients with obstructing colorectal cancer with perineural invasion $(P=0.249)$. d Overall survival for all patients with obstructing colorectal cancer without perineural invasion $(P=0.392)$ 
Table 7 Factors associated with overall survival of colorectal cancer patients with complete intestinal obstruction OS by multivariate cox regression

\begin{tabular}{|c|c|c|c|c|c|c|}
\hline & Univar & & & Multiv & & \\
\hline & $\mathrm{HR}$ & $(95 \% \mathrm{Cl})$ & $P$ & $\mathrm{HR}$ & $(95 \% \mathrm{Cl})$ & $P$ \\
\hline Stent(Y/N) & 1.016 & $0.51-2.04$ & 0.965 & 0.931 & $0.45-1.93$ & 0.848 \\
\hline Age & 0.907 & $0.47-1.76$ & 0.772 & 0.855 & $0.43-1.69$ & 0.653 \\
\hline Sex & 0.995 & $0.97-1.02$ & 0.707 & 1.001 & $0.97-1.03$ & 0.933 \\
\hline TNM stage & 1.744 & $0.84-3.62$ & 0.136 & 1.394 & $0.62-3.14$ & 0.422 \\
\hline PNI & 3.246 & $1.65-6.39$ & 0.001 & 3.245 & $1.46-7.20$ & 0.004 \\
\hline Vascular invasion & 2.063 & $1.04-4.08$ & 0.038 & 1.069 & $0.48-2.30$ & 0.87 \\
\hline Adjuvant chemotherapy & 0.779 & $0.39-1.56$ & 0.48 & 1.131 & $0.51-2.49$ & 0.76 \\
\hline
\end{tabular}

$P N I$ perineural invasion

\section{Discussion}

Our results suggest that SBTS and ES are feasible therapies for patients with CRC complicated with complete intestinal obstruction. However, patients receiving ES showed longer hospital stay, higher rates of temporary or permanent stomas, and higher incidence of adverse events after surgery than patients with SBTS. Colon metal stents did not increase the perineural invasion in the SBTS group, and the long-term oncological results and survival rates were similar between the two groups. Thus, SBTS is worth introducing in tertiary hospitals and suitable patients.

Since the use of SEMS in the early 1990s, the new method of treating CRC with malignant obstruction has gradually changed [14]. Several randomized controlled trials showed that the use of SEMS has significantly reduced the rate of enterostomy. Moreover, the proportion of laparoscopic resection has increased, which not only reduces hospital stay and speeds up post-operative recovery, but also is acceptable to patients [15-17]. In this study, the laparoscopic surgery rate in the SBTS group was obviously higher than that in the ES group (74.4\% (32/43) vs $41.3 \%(26 / 63), P=0.003)$, and the temporary stoma rate in the SBTS group was obviously lower than that in the ES group $(32.6 \%(14 / 43)$ vs $46 \%(29 / 63), P=$ $0.03)$. Several meta-analysis also confirmed that SEMS is technically safe and effective for CRC complicated with intestinal obstruction, whether as a strategy of transitional surgery or as a palliative treatment $[7,18]$. The latest edition of the World Emergency Surgery Guidelines also stated the obvious advantages of SEMS compared with ES in the treatment of palliative CRC complicated with intestinal obstruction. In patients with curable tumours complicated with obstruction, some patients can be selected when appropriate [19].

However, Thorlacius et al. believed that stent implantation is a mechanical stimulus to tumours, which may have a negative impact on the long-term survival of patients $[9,20]$. Kim et al. also reported that intestinal stent implantation may increase the rate of complication.
However, they found no significant difference in the long-term oncological results between the SBTS and ES groups, which further confirmed the clinical safety of intestinal stent in the treatment of CRC complicated with complete intestinal obstruction [21, 22]. In addition, Knight et al. concluded that SBTS does not increase tumour metastasis and spread compared with ES and reported no significant difference in the 5-year survival rate between the two group s[23]. In our previous study, a long-term follow-up of patients with colon stent perforation showed that perforation caused by colon stent does not increase the risk of peritoneal metastasis [24]. In this study, three patients had stent perforation following stent implantation, and the rate of stent perforation was $6.98 \%$, which was consistent with $0-16 \%$ reported in previous studies [25].

Perineural invasion (PNI) is a possible route for metastatic spread in various cancer types, including CRC, and Nikki et al. had confirmed and quantified it was the strong negative prognostic impact for recurrence and survival in CRC [26]. The most important result of this study is that we found that colon stents do not increase the incidence of perineural invasion in CRC patients. Compared with the ES group, the SBTS group has a lower incidence of perineural invasion (39.5\% (17 of 43 patients) vs $47.6 \%$ (30 of 63 patients), $P=0.411$ ), and the difference in the incidence of lymphatic metastasis between the two groups was not significant. However, this result is somewhat different from that obtained by a published study from Japan; the study argues that obstruction itself is associated with higher incidence of perineural invasion. The study reported that the mechanical stress of the obstruction is causing the perineural invasion. We suppose that the difference is related to the higher incidence of vascular invasion in the ES group. Some reports showed that perineural invasion affects the prognosis of CRC after resection, and a recent study showed that perineural invasion is a negative prognostic factor for stage II-III disease even in absence of nodes [27]. Another study also showed that in patients 
with malignant colonic obstruction, poor outcomes after surgery are associated with perineural invasion [28]. We analysed all factors that may affect the prognosis of patients, and the results showed that perineural invasion, vascular invasion, lymph node metastasis, and American Joint Committee on Cancer staging were all the factors influencing the survival of patients. In multivariate analysis, only perineural invasion had a significant impact on survival and prognosis, which was consistent with previous studies [29].

Previous studies have only focused on the relationship between perineural invasion and prognosis, and few studies have investigated the association between colonic scaffolds and perineural invasion. What is the innovation and difference in this study is that we not only investigated the effect of perineural invasion on patient prognosis, we also demonstrated that colon stents do not increase the incidence of perineural invasion in CRC patients, and it also provides theoretical support for the further application of colon stents in complete intestinal obstruction caused by CRC.

At the same time, this study has several limitations. First, it was a retrospective study based on a database of prospective studies. Due to the lack of randomization, different locations of tumour between groups and short interval that stents were in place, and these factors may influence the outcomes. Therefore, randomized, wellbalanced trials should be conducted to make meaningful judgments about the role of the stent in prognosis. Second, patients mainly underwent ES and gastrointestinal surgery; however, the doctors were not from the same group, and lack of uniform criteria for treatment decisions may lead to bias in choice [11]. Third, due to the limitation of follow-up time, we could not prove the impact of perineural invasion on the long-term survival of patients. Meanwhile, the long-term oncological results of stent implantation are still unclear, and studies with larger sample size and further long-term follow-up are needed. Despite these limitations, this study provides meaningful data on the safety and effectiveness of elective surgery after stent implantation.

\section{Conclusion}

Short-term stent implantation had no significant effect on perineural invasion in patients with $\mathrm{CRC}$, and the survival of post-operative tumours was similar between the ES and SBTS groups. The strategy of SBTS is safe and effective in the treatment of complete intestinal obstruction complicated by CRC.

\section{Acknowledgements}

We gratefully acknowledge all the staff members of the Department of Pathology, Union Hospital, Tongji Medical College, Huazhong University of Science and Technology, for their help and cooperation.

\section{Authors' contributions}

Yinghao Cao, Ming Yang, and Lizhao Yan contributed equally to this work, and they were considered co-first authors. Li Liu and Kailin Cai are the correspondent authors. The authors read and approved the final manuscript.

\section{Funding}

This study was supported by grants from the Science and Technology Department of Hubei Province (No.2018CFC884) and the Wu Jieping Medical Foundation of China (No.320.2710.1843)

\section{Availability of data and materials}

All data generated or analysed during this study are included in this published article.

\section{Ethics approval and consent to participate}

The ethics committee of Tongji Medical College of Huazhong University of Science and Technology approved the study. Written informed consent was obtained from the patients for the participation.

\section{Consent for publication}

The written consent is available for review by the Editor-in-Chief of this journal.Consent was taken to publish the findings. The written consent is available for review by the chief editor.

\section{Competing interests}

The authors declare that they have no competing interests.

\section{Author details}

'Department of Gastrointestinal Surgery, Union Hospital, Tongji Medical College, Huazhong University of Science and Technology, Wuhan 430022, Hubei, China. ${ }^{2}$ Department of Pathology, Union Hospital, Tongji Medical, Huazhong University of Science and Technology, Wuhan 430022, Hubei, China. ${ }^{3}$ Department of Epidemiology and Biostatistics, The Ministry of Education Key Lab of Environment and Health, School of Public Health, Tongji Medical College, Huazhong University of Science and Technology, Wuhan 430022, Hubei, China.

Received: 26 January 2020 Accepted: 25 March 2020

Published online: 22 April 2020

\section{References}

1. Bray F, Ferlay J, Soerjomataram I, Siegel RL, Torre LA, Jemal A. Global cancer statistics 2018: GLOBOCAN estimates of incidence and mortality worldwide for 36 cancers in 185 countries. CA Cancer J Clin. 2018;68:394-424.

2. Lee HJ, Hong SP, Cheon JH, Kim TI, Min BS, Kim NK, Kim WH. Long-term outcome of palliative therapy for malignant colorectal obstruction in patients with unresectable metastatic colorectal cancers: endoscopic stenting versus surgery. Gastrointest Endosc. 2011:73:535-42.

3. Ahn HJ, Kim SW, Lee SW, Lee SW, Lim CH, Kim JS, Cho YK, Park JM, Lee IS, Choi MG. Long-term outcomes of palliation for unresectable colorectal cancer obstruction in patients with good performance status: endoscopic stent versus surgery. Surg Endosc. 2016;30:4765-75.

4. Deans GT, Krukowski ZH, Irwin ST. Malignant obstruction of the left colon. Br J Surg. 1994;81:1270-6.

5. Waldron RP, Donovan IA, Drumm J, Mottram SN, Tedman S. Emergency presentation and mortality from colorectal cancer in the elderly. Br I Surg. 1986;73:214-6.

6. Kyllonen LE. Obstruction and perforation complicating colorectal carcinoma. An epidemiologic and clinical study with special reference to incidence and survival. Acta Chir Scand. 1987;153:607-14.

7. Khot UP, Lang AW, Murali K, Parker MC. Systematic review of the efficacy and safety of colorectal stents. Br J Surg. 2002;89:1096-102.

8. van Hooft JE, Fockens P, Marinelli AW, Timmer R, van Berkel AM, Bossuyt PM, Bemelman WA. Early closure of a multicenter randomized clinical trial of endoscopic stenting versus surgery for stage IV left-sided colorectal cancer. Endoscopy. 2008:40:184-91.

9. Thorlacius $\mathrm{H}$. Tumour cell dissemination following endoscopic stent insertion (Br J Surg 2007; 94: 1151-1154). Br J Surg. 2008:95:127-8 128.

10. Alford T, Ghosh S, Wong C, Schiller D. Clinical outcomes of stenting for colorectal obstruction at a tertiary centre. J Gastrointest Cancer. 2014;45: $61-5$. 
11. Siddiqui A, Cosgrove N, Yan LH, Brandt D, Janowski R, Kalra A, Zhan T, Baron TH, Repici A, Taylor LJ, Adler DG. Long-term outcomes of palliative colonic stenting versus emergency surgery for acute proximal malignant colonic obstruction: a multicenter trial. Endosc Int Open. 2017:5:E232-8.

12. Amit M, Binenbaum $Y$, Trejo-Leider L, Sharma K, Ramer N, Ramer I, Agbetoba A, Miles B, Yang $X$, Lei $D$, et al. International collaborative validation of intraneural invasion as a prognostic marker in adenoid cystic carcinoma of the head and neck. Head Neck. 2015;37:1038-45.

13. Mitsunaga S, Hasebe T, Kinoshita T, Konishi M, Takahashi S, Gotohda N, Nakagohri T, Ochiai A. Detail histologic analysis of nerve plexus invasion in invasive ductal carcinoma of the pancreas and its prognostic impact. Am J Surg Pathol. 2007;31:1636-44.

14. Morino M, Bertello A, Garbarini A, Rozzio G, Repici A. Malignant colonic obstruction managed by endoscopic stent decompression followed by laparoscopic resections. Surg Endosc. 2002;16:1483-7.

15. Targownik LE, Spiegel BM, Sack J, Hines OJ, Dulai GS, Gralnek IM, Farrell JJ. Colonic stent vs. emergency surgery for management of acute left-sided malignant colonic obstruction: a decision analysis. Gastrointest Endosc. 2004;60:865-74

16. Stipa F, Pigazzi A, Bascone B, Cimitan A, Villotti G, Burza A, Vitale A. Management of obstructive colorectal cancer with endoscopic stenting followed by single-stage surgery: open or laparoscopic resection? Surg Endosc. 2008;22:1477-81.

17. Cheung HY, Chung CC, Tsang WW, Wong JC, Yau KK, Li MK. Endolaparoscopic approach vs conventional open surgery in the treatment of obstructing left-sided colon cancer: a randomized controlled trial. Arch Surg. 2009;144:1127-32.

18. Arezzo A, Passera R, Lo SG, Verra M, Bonino MA, Targarona E, Morino M. Stent as bridge to surgery for left-sided malignant colonic obstruction reduces adverse events and stoma rate compared with emergency surgery: results of a systematic review and meta-analysis of randomized controlled trials. Gastrointest Endosc. 2017:86:416-26.

19. Pisano M, Zorcolo L, Merli C, Cimbanassi S, Poiasina E, Ceresoli M, Agresta F, Allievi N, Bellanova G, Coccolini F, et al. 2017 WSES guidelines on colon and rectal cancer emergencies: obstruction and perforation. World J Emerg Surg. 2018;13:36.

20. Koch M, Kienle P, Sauer P, Willeke F, Buhl K, Benner A, Lehnert T, Herfarth C, von Knebel DM, Weitz J. Hematogenous tumor cell dissemination during colonoscopy for colorectal cancer. Surg Endosc. 2004;18:587-91.

21. Kim HJ, Choi GS, Park JS, Park SY, Jun SH. Higher rate of perineural invasion in stent-laparoscopic approach in comparison to emergent open resection for obstructing left-sided colon cancer. Int J Color Dis. 2013;28:407-14.

22. Sabbagh C, Browet F, Diouf M, Cosse C, Brehant O, Bartoli E, Mauvais F, Chauffert B, Dupas JL, Nguyen-Khac E, Regimbeau JM. Is stenting as "a bridge to surgery" an oncologically safe strategy for the management of acute, left-sided, malignant, colonic obstruction? A comparative study with a propensity score analysis. Ann Surg. 2013;258:107-15.

23. Knight AL, Trompetas V, Saunders MP, Anderson HJ. Does stenting of leftsided colorectal cancer as a "bridge to surgery" adversely affect oncological outcomes? A comparison with non-obstructing elective left-sided colonic resections. Int J Color Dis. 2012;27:1509-14.

24. Cao Y, Deng S, Wu K, Zheng H, Cheng P, Zhang J, Chen L, Tang S, Wang P, Liao $X$, et al. Oncological consequence of emergent resection of perforated colon cancer with complete obstruction after stent insertion as a bridge to surgery. Int J Color Dis. 2019;34:545-7.

25. Nitta T, Kataoka J, Ohta M, Fujii K, Tominaga T, Inoue Y, Kawasaki H, Ishibashi T. Clinical outcomes of self-expandable metal stent (SEMS) placement as palliative treatment for malignant colorectal obstruction: a single-center study from Japan. Ann Med Surg (Lond). 2017;19:33-6.

26. Knijn N, Mogk SC, Teerenstra S, Simmer F, Nagtegaal ID. Perineural invasion is a strong prognostic factor in colorectal cancer: a systematic review. Am J Surg Pathol. 2016;40:103-12.

27. Mirkin KA, Hollenbeak CS, Mohamed A, Jia Y, El-Deiry WS, Messaris E. Impact of perineural invasion on survival in node negative colon cancer. Cancer Biol Ther. 2017;18:740-5.

28. Mulcahy HE, Skelly MM, Husain A, O'Donoghue DP. Long-term outcome following curative surgery for malignant large bowel obstruction. Br J Surg. 1996;83:46-50

29. van Wyk HC, Going J, Horgan P, McMillan DC. The role of perineural invasion in predicting survival in patients with primary operable colorectal cancer: a systematic review. Crit Rev Oncol Hematol. 2017;112:11-20.

\section{Publisher's Note}

Springer Nature remains neutral with regard to jurisdictional claims in published maps and institutional affiliations.
Ready to submit your research? Choose BMC and benefit from:

- fast, convenient online submission

- thorough peer review by experienced researchers in your field

- rapid publication on acceptance

- support for research data, including large and complex data types

- gold Open Access which fosters wider collaboration and increased citations

- maximum visibility for your research: over $100 \mathrm{M}$ website views per year

At BMC, research is always in progress.

Learn more biomedcentral.com/submissions 